\title{
FERNANDO DE AZEVEDO: UMA NOVA ORGANIZAÇÃO DO TRABALHO DIDÁTICO PARA UMA ESCOLA RENOVADA (1927-1931)
}

\author{
Silvia Helena Andrade de Brito ${ }^{1}$ \\ Maria Angélica Cardoso ${ }^{2}$ \\ Rosely Gonçalves de Oliveira ${ }^{3}$
}

\section{RESUMO}

Este artigo tem como objeto a proposta para a organização do trabalho didático em Fernando de Azevedo (1894-1974). Nesse sentido, o objetivo desse trabalho é apresentar e problematizar a proposta de Fernando de Azevedo sobre o trabalho didático na sociedade capitalista. Para atingir esse objetivo, foram utilizadas como fontes primárias as obras de Fernando de Azevedo, bem como fontes secundárias, necessárias ao enriquecimento das reflexões aqui apresentadas. Assim, na primeira parte do artigo serão discutidas as categorias que presidirão as análises sobre as propostas azevedianas: trabalho didático e organização do trabalho didático. O segundo momento versa sobre os quatro elementos da organização do trabalho didático que serão analisados: a relação educativa; os recursos didáticos; o espaço físico e as políticas educacionais. À guisa de conclusão, enfatize-se que, apesar da crítica de Fernando de Azevedo à organização do trabalho didático na chamada escola tradicional e a proposta renovadora voltada para transformar esta organização, o viés liberal de sua análise estabelece os limites de suas propostas, que não chegaram ao âmago do problema, ou seja, foi incapaz de desvelar o caráter orgânico do trabalho didático em relação ao capitalismo, enquanto forma de organização da vida social.

Palavras-chave: Organização do trabalho didático; Fernando de Azevedo; Escola Nova.

\section{FERNANDO DE AZEVEDO: A NEW ORGANIZATION OF DIDACTIC WORK FOR A RENEWED SCHOOL (1927-1931)}

\begin{abstract}
This article has like object the proposal of the didactic work organization in Fernando de Azevedo (1894-1974). Regarding it, the objective of this work is presenting and problematizing Fernando de Azevedo's proposal about didactic work in the capitalist society. In order to achieve these objectives, the works of Fernando de Azevedo, as well as secondary sources, were used as primary sources, necessary to enrich the reflections presented here. Thus, in the first part of the article the categories that will preside over the analyzes of the azevedian proposals are dicussed: didactic work and didactic work organization. The second moment is about the four elements of the organization of didactic work that will be analyzed: the educational relationship; didactic resources; physical space and educational policies. As a conclusion, it should be emphasized that, despite Fernando de Azevedo's critique of the organization of didactic work in the so-called traditional school, and the renovating proposal aimed at transforming this organization, the liberal pattern of his analysis establishes the limits of its proposals, which do not reach the core of the problem, it means, it is unable to reveal the organic character of didactic work in relation to the capitalism as a form of social life organization.
\end{abstract}

Keywords: Organization of didactic work; Fernando de Azevedo; New School. 


\title{
Introdução
}

\begin{abstract}
[A reforma] Adotando por base de todo o ensino a atividade investigadora e experimental do aluno, [...] não só levou à escola primária os processos do ensino superior, inteiramente apoiado hoje na observação, nas pesquisas e experiências, como transformou a escola (escola do trabalho), em que se aprende trabalhando, em uma colmeia de atividades educativas (AZEVEDO, 1958, p. 81).
\end{abstract}

Com essas palavras, em conferência realizada em 21 de novembro de 1929, em um evento organizado pela Federação Nacional da Sociedade de Educação ${ }^{4}$, Fernando de Azevedo (1894-1974) comentava as proposições para a reforma do trabalho didático, que foram objeto de suas intervenções à frente da Diretoria-Geral da Instrução Pública do Distrito Federal, cargo que ocupou entre 17 de janeiro de 1927 e outubro de 1930, quando eclodiu a Revolução de 1930. Foi durante sua permanência nesse cargo que foi aprovada a Lei ${ }^{\circ} 3281$, de 23 de janeiro de 1928, que reformava, com base nas diretrizes da Escola Nova, o ensino primário, normal e a educação profissional na cidade do Rio de Janeiro (AZEVEDO, 1958).

Com base nas reflexões elaboradas por Azevedo acerca de seu entendimento sobre aquilo que marcaria o trabalho didático para os reformadores, o presente trabalho tem como objeto a proposta para a organização do trabalho didático, formulada e discutida pelo referido escolanovista, entre os anos 1930 e $1970^{5}$. Nessa direção, os objetivos foram assim delineados: a) apresentar a proposta de Fernando de Azevedo, considerada a partir da categoria organização do trabalho didático; b) problematizar a mesma, tendo como parâmetro as condições em que se realiza o trabalho didático na sociedade capitalista.

Tendo em vista estes objetivos, esta análise se justifica pela proposição de um novo olhar, qual seja, retomar as proposições azevedianas sob a luz da categoria organização do trabalho didático, cujos aspectos constitutivos são: 1) a relação educativa; 2) os elementos de mediação que se fazem necessários para que tal relação se estabeleça (o texto escolar e outros recursos didáticos como as políticas educacionais, os planos e programas, as bibliotecas, o cinema, o rádio etc.); 3) e as edificações escolares. Buscou-se com isso desvelar a nova relação educativa, proposta pelo escolanovista para a formação de um novo homem, tendo como bases teóricas as propostas de Marx, nas quais se baseia Alves para analisar a singularidade e particularidade da questão educacional.

Em Marx (1980), a ciência da história desvela o movimento universal que se manifesta no singular, indo além das aparências e mostrando que não bastam definições nas quais as coisas se encaixam, mas a análise precisa desvelar as funções assumidas pelas coisas, funções estas que são determinadas por relações sociais e que se expressam, no pensamento, por meio de categorias determinadas. Em Alves (2001; 2005; 2012), o trabalho é tomado como categoria mais geral e inclusiva, o trabalho didático e a organização do trabalho didático como categorias subordinadas que se transformam, acompanhando e sendo determinadas pelas mudanças mais gerais da sociedade, em cada momento histórico.

Para atingir os objetivos propostos, foram utilizadas como fontes primárias três obras de Fernando de Azevedo: o texto Novos caminhos e novos fins: a nova política de educação no Brasil - subsídios para uma história de quatro anos, publicada originalmente em $1932^{6}$, onde Azevedo comenta sua passagem pela Diretoria-Geral da Instrução Pública do Distrito Federal, e os acontecimentos que se deram quando da proposição, aprovação e implantação daquela que ficou conhecida como a Reforma Fernando de Azevedo, entre 1927 e 1930 (CAMARA, 2011); A educação e seus problemas (2 volumes, 1937, primeira edição) ${ }^{7}$ e 
História de minha vida, de 1971, relato autobiográfico da trajetória de Fernando de Azevedo. Também foi utilizado como fonte primária o Código de Educação do Estado de São Paulo, aprovado em 21 de abril de 1933, resultado da permanência de Azevedo à frente da DiretoriaGeral da Instrução Pública do referido estado. Além disso, foram compiladas fontes secundárias, necessárias ao enriquecimento das reflexões aqui apresentadas.

Em termos de organização, o artigo foi dividido em três partes. Na primeira parte trabalhou-se com as categorias que presidiram as análises sobre as propostas azevedianas, a saber: trabalho didático e organização do trabalho didático, tal como apresentadas a partir das investigações de Alves $(2001 ; 2005 ; 2012)$. O segundo momento deste texto versa sobre os quatro elementos da organização do trabalho didático analisados: a) a relação educativa; b) os elementos de mediação, como é o caso de planos e programas, com ênfase no principal instrumento de trabalho do professor - os textos escolares - sendo que também serão apresentados outros instrumentos didáticos, como as bibliotecas, o rádio, entre outros; c) as edificações escolares; d) e as políticas educacionais, questão frequente nas reflexões de Azevedo.

Por fim, fechando o artigo, na terceira e última parte do mesmo têm-se as considerações finais sobre as reflexões anteriormente expostas.

\section{O que são trabalho didático e organização do trabalho didático}

Como afirmado anteriormente, para a problematização das propostas de Fernando de Azevedo, tendo como base teórica a ciência da história (MARX; ENGELS, 2007), foram fundamentais as categorias trabalho didático e organização do trabalho didático, apresentadas a partir das investigações de Alves (2001; 2005; 2012).

Partindo da categoria mais geral e inclusiva, trabalho, Alves pondera que, da mesma forma que outras produções humanas, a educação também é social e historicamente produzida, por meio do trabalho. De fato, Marx ressalta a importância do trabalho como elemento fundante da vida social, uma vez que tudo o que o homem produz, seja material ou imaterial, é produzido por meio do trabalho (MARX, 1974). Assim, cabe falar de trabalho didático, "[...] categoria subordinada [em relação à categoria trabalho], desde o momento em que é produzida no campo da educação" (ALVES, 2005, p. 10).

$\mathrm{Na}$ mesma direção, entende-se que a organização do trabalho didático, em seus elementos constituintes, ao mesmo tempo em que está presente em todas as sociedades, se transforma em cada uma delas, acompanhando e sendo determinada pelas mudanças mais gerais de cada modo de produção e das respectivas forma/conteúdo que assume o trabalho, em seu interior. Assim, segundo Alves,

No plano mais genérico e abstrato, qualquer forma histórica de organização do trabalho didático envolve, sistematicamente, três aspectos: 
a) ela é, sempre, uma relação educativa que coloca, frente a frente, uma forma histórica de educador, de um lado, e uma forma histórica de educando(s), de outro;

b) realiza-se com a mediação de recursos didáticos, envolvendo os procedimentos técnico-pedagógicos do educador, as tecnologias educacionais pertinentes e os conteúdos programados para servir ao processo de transmissão do conhecimento;

c) e implica um espaço físico com características peculiares, onde ocorre (ALVES, 2005, pp. 10-11, grifos do autor).

Em se tratando do capitalismo, a escola moderna, ao se tornar a forma hegemônica assumida pelo processo educacional, à medida que se constituiu na perspectiva de escola para todos, erigiu-se, principalmente a partir do século XVII, marcada por determinadas características, se pensada a partir dos três aspectos elencados acima por Alves. Ainda segundo o mesmo autor, quem melhor projetou essa nova instituição educacional, a escola moderna, ainda nos meados do mesmo século XVII, foi João Amós Coménio (1592-1670), bispo morávio, que apresentou, em sua Didáctica Magna, a proposta de como se organizaria o trabalho didático na sociedade capitalista:

1) uma dada relação educativa, pautada em uma forma histórica de educandos, compondo coletivos de alunos, organizados a partir de critérios que permitiriam a formação de classes homogêneas e o ensino seriado, bem como a articulação do processo educativo a partir de uma escola graduada, por um lado; e, por outro, uma forma histórica de educador, o professor, cuja atividade seria adequada a esses coletivos, na medida em que se tornaria um trabalhador especializado, cuja atividade se voltaria a uma parte ou etapa da escolarização;

2) para que se realizasse a relação educativa proposta para a escola moderna, era necessário o surgimento de novos instrumentos de trabalho, sobretudo "Uma só coisa é de extraordinária importância, pois, se ela falta, pode tornar-se inútil toda a máquina, ou, se está presente, pode pô-la toda em movimento: uma provisão suficiente de livros pan-metódicos" (COMÉNIO, 2006, p. 469, grifos nossos).

Ou seja, o que garantiria a fidelidade do professor ao novo método, propugnado para a escola moderna, seria o manual didático. Para tal, previa Coménio não apenas a presença dos manuais didáticos em número suficiente para todos os alunos, como também os livrosroteiros (COMÉNIO, 2006, p. 460), voltados para os professores, “[...] que os aconselhem quanto ao que hão-de fazer, em que lugar e de que modo, para que não se caia em erro [...], para [que os professores] aprendam a servir-se bem daqueles". Assim, a garantia do sucesso no uso do novo método repousava no instrumento de trabalho, elemento central na relação educativa que ora se propunha.

Partindo desse pressuposto, Alves $(2001 ; 2005)$ enfatiza o papel ao mesmo tempo centralizador e excludente do manual didático na proposta comeniana: síntese dos conteúdos a serem transmitidos na escola, ele cada vez mais iria se tornando o instrumento de trabalho central na organização do trabalho didático da escola moderna, promovendo as condições necessárias à simplificação e objetivação crescentes do trabalho didático. Simultaneamente, nesse processo em que o manual didático vai expandindo sua presença, vão sendo abandonados outros recursos didáticos, tais como os textos clássicos, as antologias, os dicionários, os compêndios (e, consequentemente, o espaço destinado a colocar os alunos em contato com os mesmos, as bibliotecas escolares), enquanto outros não conseguem penetrar nos muros da escola, embora façam parte do cotidiano da sociedade capitalista (a exemplo dos meios de comunicação de massa, se se toma a primeira metade do século XX, no Brasil). 
3) Outro elemento importante destacado por Alves ao tratar da organização do trabalho didático é o espaço físico, visto que o coletivo de alunos, a presença de séries graduadas, as escolas voltadas para diferentes níveis de escolarização, entre outros, irão demandar a destinação de edificações que serão projetadas e construídas para abrigar a nova instituição.

Lembra Cordeiro (1995, p. 17) que:

[...] a arquitetura, diferente de outras manifestações artísticas, possui "em si" uma função utilitária, para a qual se pressupõe uma intenção, um "paraque-serve". Esse "para-que-serve" determina a utilidade do edifício e está eivado de interesses históricos que transcendem o período de sua construção, como exemplar "vivo", na paisagem urbana, das soluções dadas aos problemas de sua época.

Por isso, acompanhando as diferentes proposições de materialização da escola moderna, diferentes edifícios escolares foram projetados, na intenção de abrigar a organização do trabalho didático que ora se delineava;

4) Encerrando sua exposição, e ainda tratando dos elementos presentes na organização do trabalho didático, Alves (2012) enfatiza que:

E para que não se alegue omissão de qualquer aspecto incluído entre os elementos integrantes da 'organização do trabalho didático', acrescente-se que também o aparato de apoio administrativo produzido pela escola moderna tornou-se indispensável à realização de sua forma histórica radicada em Coménio. É o que ficará claro, mais adiante, quando a discussão aprofundar as consequências da divisão manufatureira do trabalho didático. A extensa estrutura administrativa constitui particularidade da escola moderna e só ganhou peso em decorrência do caráter complexo da instituição que, desde o século XVII, assumiu a função de 'ensinar tudo a todos', segundo a expressão de Coménio. Privilégio de poucos, até então, a educação de crianças e de jovens nunca a demandara antes (ALVES, 2012, p. 170).

Tal estrutura, fruto do processo de divisão do trabalho didático, conforme Alves (2012) realizou, no âmbito dessa esfera, tendência que é inerente ao modo de produção capitalista, na medida em que a especialização das tarefas, em todos os setores da vida social, separa e distingue as esferas de programação e execução. Nesse sentido, tal como previra Coménio, o professor se tornou, preso ao manual didático, cada vez mais o executor de diretrizes e políticas emanadas das esferas centrais de organização do trabalho didático, tendo a frente o Estado. Ao mesmo tempo, o processo de especialização faz surgirem novos personagens, como são os diretores, os conselhos escolares, as comissões responsáveis pelas deliberações curriculares, pela escolha e compra de manuais didáticos, entre outros, sendo estes elementos cada vez mais presentes na história da educação no Brasil, principalmente a partir da Primeira República (NAGLE, 2001).

Concluindo a apresentação das bases teóricas sobre as quais se fundamentou este artigo, enfatize-se que trabalho, trabalho didático e a organização do trabalho didático (com os vários elementos presentes em seu interior - a relação educativa, os elementos de mediação, as edificações escolares, as políticas educacionais, entre outros) constituem-se, são construídos, histórica e social, em uma perspectiva dialética, considerando, como lembra 
Kosik (1976, p. 37), “[...] que a própria realidade, na sua estrutura, é dialética”. Nesse sentido, não há como materializar uma nova organização do trabalho didático sem que a mesma se projete em políticas educacionais, colocando a ação do Estado como elemento central para o trabalho didático. Da mesma forma, uma nova relação educativa está intrinsicamente relacionada aos elementos de mediação que a constituem enquanto relação social e, na escola moderna, será o texto escolar quem determinará, pela sua centralidade, as condições em que estarão os professores e seus coletivos de alunos.

Uma última questão, de grande importância, tem que ser destacada antes de se partir para a apresentação do pensamento de Fernando de Azevedo sobre a organização do trabalho didático. Coménio de fato anunciou claramente o espaço cultural onde se centra a tônica da organização do trabalho didático, o manual didático,

Porém essa tendência restringiu-se às regiões dominadas pela Reforma Protestante. Nos espaços culturais ligados à Contrarreforma, textos nada ou pouco especializados ainda eram utilizados desde os albores da escola moderna até o século XIX. Isso se manifestou inclusive na singularidade histórica brasileira, momento em que o câmbio para os manuais didáticos se constitui em processo de longa duração. Depois de diversas transições, o manual didático adentrou incompleto o século XX e só se realizou plenamente na sua segunda metade (ALVES, 2015, p. 10).

Importa assinalar, nessa direção, que Fernando de Azevedo e o movimento escolanovista encontram-se exatamente no momento em que os manuais didáticos já se faziam presentes, principalmente no ensino primário - as diferentes cartilhas utilizadas desde o século XIX e na primeira metade do século XX atestam isso (FERNANDES, 2014; SANTOS, 2013). No ensino secundário (BRITO et al., 2012), contudo, outras modalidades de textos escolares, principalmente compêndios, ainda eram hegemônicos, como a observação de Alves (2015) enfatiza.

Tendo em vista as categorias aqui expostas, parte-se para a apresentação e análise das propostas azevedianas.

\section{Fernando de Azevedo e a Escola Nova: a defesa de uma nova organização do trabalho didático}

Com o fim da Primeira Guerra Mundial e com o processo de industrialização, o mundo capitalista passou por uma imensa transformação, que alcançou também o Brasil. Nesse contexto de transformações, diferentes parcelas da sociedade civil no país passaram a se organizar em torno de melhores condições de vida e, também, por uma escola diferente daquela até então oferecida à população brasileira naquele momento histórico, conformando, entre outros movimentos, aquele que Nagle (2001) denomina como otimismo pedagógico:

A segunda fase de um histórico do escolanovismo no Brasil compreende a década de 1920. Se a primeira é a fase preparatória, a segunda é a da difusão e das realizações. Nesta fase se encontra a difusão sistemática dos ideais da Escola Nova, período em que a literatura educacional, além de se expandir, se altera qualitativamente, dada a frequência com que se 
publicam trabalhos sobre o assunto referentes à "nova pedagogia". (NAGLE, 2001, p. 310).

E como lembra o mesmo autor, foi nesse momento histórico que se realizaram as primeiras reformas, visando "[...] realizar o novo modelo de estruturação das instituições escolares" (NAGLE, 2001, p. 310). Para responder a essas novas demandas, seria preciso criar e aparelhar escolas, expandir e equipar suas bibliotecas, bem como preocupar-se com um conjunto de questões associadas à formação de professores: essas foram algumas das propostas levantadas por Fernando de Azevedo (1948; 1958), como forma de materializar a nova educação para a sociedade em mudança ou, em outros termos, propor e levar à prática uma nova organização do trabalho didático.

São três os princípios básicos propostos por Fernando de Azevedo para a reforma na educação. Em primeiro lugar, a extensão da escola a todas as crianças em fase escolar, a proposta da escola única; em segundo, a articulação entre os vários níveis de ensino e, em terceiro lugar, a adaptação ao meio, ou seja, a escola urbana dando mais atenção ao processo de industrialização e a escola rural voltada para as atividades agrícolas.

Assim sendo, a escola, segundo Azevedo (1958), seria uma sociedade em miniatura, preparando o sujeito para a inserção em seu meio, seja no mercado de trabalho, nas relações sociais e até mesmo no âmbito político. Para tal, haveria dentro do espaço escolar, ambientes que pudessem abranger a totalidade da experiência social: consultórios médicos e odontológicos, cinema, a rádio escola, etc., para que o aluno aprendesse a viver em sociedade para qual ele estava se formando ${ }^{8}$. Aqui se propõe uma nova relação educativa, na qual o indivíduo seria preparado para a fase de industrialização e urbanização que tomava conta do país.

Nessa direção, o autor projetou os elementos de organização do trabalho didático que marcariam a renovação daquela que foi denominada, pelos escolanovistas, de "escola tradicional". Investigou-se nos escritos azevedianos o primeiro destes elementos: a relação educativa.

\section{Relação educativa}

Para Alves (2005), cada época, concretamente, produz a relação educativa que lhe é própria, envolvendo uma forma histórica de educador e uma forma histórica de educando. $\mathrm{Na}$ escola moderna, professor e coletivos de alunos são as formas históricas concretas presentes na relação educativa. São essas formas concretas de educador e de educando, os elementos dos quais partiu Fernando de Azevedo para pensar sua proposta de uma nova relação educativa.

Para que tal relação educativa se efetivasse, conforme Azevedo (1958, p. 72), não se tratava apenas de uma reforma de métodos pedagógicos, mas de uma "[...] reorganização radical de todo aparelho escolar, em vista de uma nova finalidade pedagógica e social". Daí a reforma assumir como ideal, segundo a moderna concepção social, três aspectos básicos: 1) o princípio da escola única, comentado anteriormente; 2) a escola do trabalho; 3) a escola comunidade.

Frente a esses princípios, a reforma dá ao professorado uma nova incumbência: não ser mais um mero transmissor de conteúdos e sim:

[...] transmitir às novas gerações, e para o qual converge todo o plano de organização escolar, o ideal de ação: o espírito de iniciativa, a consciência da necessidade do esforço para afirmar-se, o gosto, o hábito e a técnica do 
trabalho e o respeito à personalidade de outrem, pelo sentimento e pelo hábito do trabalho em cooperação (AZEVEDO, 1958, p. 72).

Nas palavras do autor, a escola não seria mais um auditório, mas um laboratório no qual o professor ensinaria pelo trabalho, estimulando, orientando e praticando com os alunos todas as atividades escolares. Dessa forma, a escola, além de criar e desenvolver o sentimento democrático (escola única) se transformaria num instrumento de reorganização econômica, pela escola do trabalho.

Assim, a nova proposta baseava toda a educação na atividade criadora e pesquisadora do aluno, afirma Azevedo (1958). Por isso desde a escola primária, o caráter educativo deve revestir-se dessa nova concepção, provocando modificações profundas, tornando mais elevada e mais árdua a função do mestre e estreitando suas relações com os alunos.

O professor deve assumir um novo papel "[...] que, para manter com disciplina e sem fadiga a atividade livre e constante dos alunos, tem que ser um despertador do interesse não somente com fonte estimuladora da atividade, mas também como a fonte única de disciplina na escola do trabalho" (AZEVEDO, 1958, p. 74).

Ora, sabemos que a relação educativa põe, de um lado, uma forma histórica de educador e, do outro lado, uma forma histórica de educando. Assim, à nova forma de educador corresponde uma nova forma de educando. Sob o prisma do terceiro ideal - escola comunidade - a Escola Nova "se propõe a ensinar a viver em sociedade e a trabalhar em cooperação", com o incentivo ao trabalho coletivo e à divisão de responsabilidades. Além disso, o aluno, a partir dos ideais escolanovistas, "observa, experimenta, projeta e executa" enquanto o professor estimula sua consciência, orienta e colabora, conduzindo-o em suas investigações e experiências. Essa nova relação educativa proposta por Azevedo, baseada numa experiência coletiva de trabalho, orientada por um profissional especialmente formado para tal, deveria atender às funções sociais propostas para a escola naquele momento: formar o homem para o trabalho urbano e industrial.

Fernando de Azevedo (1958, p. 80) reconhece, contudo, que o “[...] professorado não se habilitou, nas escolas em que se formou, para as exigências da nova organização", mas, "a escola tecnológica de mestres e contramestres, [...] e a Escola Normal, remodelada em suas futuras instalações, é que serão os grandes centros de preparação e disseminação da mestrança e do professorado incumbidos da realização integral dos novos ideais".

Por fim, ressalte-se como elemento importante neste debate o posicionamento de Azevedo, indo para além de uma visão simplista de que, com o advento da Escola Nova, advoga-se tão somente a centralidade da criança na relação educativa, favorecida pela perspectiva de respeito aos interesses do aluno. Considerando que Fernando de Azevedo, além das influências bastante conhecidas do pensamento dukheiminiano (EVANGELISTA \& LIMA, 2008; entre outros autores que tratam sobre a questão), teve acesso e incorporou o pensamento de John Dewey (SILVA, 2016; TOTTI, 2013), é neste último que se encontra uma reflexão mais alongada sobre as proposições do escolanovismo no que tange a relação educativa. Declara Dewey em um dos seus textos mais conhecidos, A criança e o currículo:

Se, mais uma vez, a "educação antiga" cuidou de ignorar a qualidade dinâmica, a força em desenvolvimento inerente à experiência presente da criança e, por conseguinte, assume que a direcção e o controlo são apenas uma questão de colocar a criança arbitrariamente num dado caminho e força-la a seguir por aí, a "nova educação" está em risco de pegar a ideia de desenvolvimento de uma forma demasiado formal e vazia. Espera-se que a criança "desenvolva" este ou aquele facto ou verdade a partir de sua própria mente. [...] Nada se desenvolve do nada; nada senão a imperfeição 
pode se desenvolver da imperfeição e é certamente isso o que acontece quando deixamos a criança a si própria (DEWEY, 2002, p. 168, grifos nossos).

Nesse sentido, não se trata de um trabalho didático não diretivo mas, como afirma Dewey (2002, p. 168) existe direcionamento nessa atividade, considerando que cabe a esta direção "[...] selecionar os estímulos apropriados para os instintos e os impulsos que é desejável utilizar na conquista de novas experiências". Para tal, necessitar-se-ia de um profissional capacitado, com base técnica adequada para proceder a essa seleção - isto é, um professor não só versado nos conteúdos próprios a sua de área de atuação - mas também profundo conhecedor dos novos instrumentais proporcionados pelas Ciências Sociais e, sobretudo, para entender o desenvolvimento e peculiaridades infantis, conhecedor da Psicologia.

Por isso Azevedo, como outros escolanovistas, enfatiza a formação de professores como elemento central para o sucesso do empreendimento da Escola Nova. No caso da Sociologia, conforme exposto no prefácio de um de seus compêndios, Princípios de Sociologia, faz-se necessário um professor presente na relação educativa para '[...] 'fazer' observar, investigar e refletir [...]. Essa iniciação nos trabalhos de campo (fieldworks) e na pesquisa social, só o professor pode e deve dá-la" (AZEVEDO, 1935, p. 27, grifos do autor). Assim, longe de estar ausente ou limitado à exposição de conteúdos, o professor escolanovista seria peça central na relação educativa que, embora tendo o aluno e seu conhecimento como ponto de partida, pretende fazer dessa experiência elemento mediador para a ampliação e aquisição de novo conhecimento. Tais elementos são importantes, pois que esta nova visão sobre a relação educativa vai articular-se com a proposta azevediana acerca dos recursos didáticos, como será exposto a seguir.

\section{A mediação dos recursos didáticos}

Conforme Alves (2005), cada época produz também os recursos didáticos e o espaço físico que lhe são pertinentes, dialeticamente inter-relacionados a uma dada relação educativa. Nessa direção, será abordado agora, então, o segundo aspecto da organização do trabalho didático, que envolve as mediações presentes no desenvolvimento do mesmo, necessárias à nova relação educativa proposta por Azevedo.

É importante lembrar que, após analisar e tecer críticas aos aspectos da escola tradicional, por meio do Inquérito sobre a Instrução Pública, pesquisa realizada em São Paulo, em 1926 (AZEVEDO, 1960), Azevedo elaborou a sua proposta educacional, primeiro para o Distrito Federal, como já citado, e depois para o estado de São Paulo. Muitos foram os "novos" recursos didáticos propostos. Aqui serão tratados dois destes recursos: os programas e conteúdos para o ensino primário, e a questão dos livros de texto e dos livros escolares, forma como Azevedo denomina os manuais didáticos, no âmbito da escola tradicional, e os textos escolares a serem utilizados na escola nova, respectivamente.

\subsection{Os planos e programas}

Antes de se tratar sobre planos e programas na obra de Fernando de Azevedo, cabe definir estes termos. Conforme o dicionário, por programa entende-se a "[...] lista total das disciplinas que compõem um curso; discriminação dos tópicos sobre os quais versam essas disciplinas" (HOUAISS; VILLAR, 2001, p. 2307) ou o sistema e a distribuição das matérias 
de um determinado (a) curso/cadeira acadêmico (a). Enfim, na escola, o programa está sempre relacionado à distribuição das disciplinas e de seus conteúdos.

É sob esta ótica que Fernando de Azevedo teceu suas críticas aos programas. Para ele, os programas escolares seriam incompatíveis com os ideais da Escola Nova. Nesta, em que a atividade é aproveitada como instrumento de educação e de ensino, não haverá programas, mas plano de estudos.

Azevedo (1958) afirma que o programa não pode fixar a matéria a ensinar, a não ser em torno de três ou quatro grandes centros de interesse, como por exemplo, a natureza, o trabalho, a sociedade; pois, é em torno desses centros, que se desenvolvem e se alargam os conhecimentos como uma ideia em marcha, partindo do particular para o geral, das coisas mais elementares e concretas para as ideias abstratas, adequando-se assim o conteúdo às condições de desenvolvimento do aluno.

Em relação aos programas e conteúdos para o ensino primário, de acordo com Azevedo (1958, p. 75), “[...] o desenvolvimento do aspecto social da educação imprimiu à escola uma nova finalidade, para cuja realização se propuseram e se experimentaram 'meios' apropriados". A adoção dos princípios básicos da Escola Nova implicou na rejeição dos meios não condizentes aos novos fins propostos e, por consequência, na revisão dos métodos pedagógicos, continua Azevedo (1958).

Considerando que o ponto de partida da Escola Nova é sempre a observação, faz-se necessário que o professor comece a ensinar o aluno a observar, pondo-o em contato constante com as coisas e os fatos. Para tanto, as excursões escolares, os museus e o cinema educativo constituem meios, entre tantos outros, abrindo ao aluno novos campos para sua observação.

Como não se aprende a observar senão pelo hábito de observação direta e essa não pode ocorrer senão sobre as coisas que estão ou podem estar ao alcance dos alunos, os planos escolares foram elaborados de acordo com esse princípio, ou seja, "[...] o princípio do meio imediato. A atividade deve ser exercida sobre a realidade viva ou sobre as coisas como a casa, a escola, a região com que o aluno tem contato direto" (AZEVEDO, 1958, p. 75). Portanto,

[...] as matérias que constituem o curso primário não são ensinadas isoladamente, mas em conjunto, agrupadas, associadas em torno de centros de interesse. É o princípio da concentração dos estudos em torno de centros de interesse, também chamada ensino global ou concêntrico, que presidiu à elaboração do novo plano de estudos (AZEVEDO, 1958, p. 76).

Como se pode observar, Azevedo explicita porque os programas escolares seriam incompatíveis com os ideais da Escola Nova, e o porquê desenvolver-se o ensino global, por meio de planos. Além disso, na escola tradicional o aluno limitava-se a conhecer pelo material que lhe dava o professor; na Escola Nova, ele parte desse material, mas deve exprimir o que observou. Este trabalho "[...] satisfaz a tendência e a necessidade do aluno de exprimir-se e de afirmar-se". Nesse contexto,

[...] a linguagem (oral, escrita e musical), o desenho, o trabalho manual (especialmente a modelagem), ou, por outros termos, a palavra, a linha e a matéria-prima são os grandes elementos de expressão. O desenho os trabalhos manuais, na escola do trabalho, baseada sobre a atividade pessoal do aluno, tem o grande relevo que lhes dá a finalidade da educação orientada para os novos ideais (AZEVEDO, 1958, p. 77). 
Assim, além de defender a utilização de todos os recursos didáticos que possam alargar o processo de aprendizagem, no Decreto n. 5.884, de 21 de abril de 1933, que instituiu o novo Código de Educação do Estado de São Paulo, aprovado durante a gestão de Azevedo, prescreve-se que os "manuais escolares" devem ser instrumentos auxiliares cedendo, sempre que possível à preferência, no trabalho didático, aos exercícios que desenvolvam o poder de criação, investigação e crítica do aluno. E ao professor caberia ser "[...] uma força viva, que domine os alunos, colaborando com eles, orientando as suas tendências pessoais e tirando partido de seus próprios defeitos, para a expressão original do seu pensamento" (AZEVEDO, 1958, p. 77).

Cabe observar, portanto, que a proposta azevediana de formação abrangente para o professor, que lhe permita conduzir o processo ensino-aprendizagem de forma a ampliar o conhecimento do aluno, de acordo com suas possibilidades, encontra sua contrapartida, no âmbito do planejamento do trabalho didático, numa equipe de apoio que encaminhe a organização do trabalho didático nessa mesma direção. A perspectiva de trabalho com os centros de interesse, o ensino global, exige não só um coletivo de professores, nas instituições escolares, voltados nessa direção, como diretores, equipes de apoio e infraestrutura organizadas para tal, encaminhando assim a discussão do autor para o campo das políticas educacionais, o que será tratado mais adiante neste artigo.

Antes de se deixar a sala de aula, no entanto, cabe analisar aquele que, desde a proposta de Coménio, já era indicado como o principal instrumento de trabalho do professor: o texto escolar. Estando Fernando de Azevedo num momento de transição em termos de organização do trabalho didático, tendo produzido textos escolares para o ensino secundário e normal $^{9}$, e projetando um trabalho didático que exigiria um professor não apenas competente no que diz respeito ao conhecimento específico de sua área de atuação, mas ainda versado naquilo que seria os elementos próprios às novas características pensadas pelo escolanovismo para o trabalho didático - o acesso às Ciências Sociais e à Psicologia - qual papel o autor atribuiu aos textos escolares?

\subsection{Os livros escolares, os livros de texto e outros recursos didáticos}

Para Azevedo, todos os recursos colocados à disposição da escola, fruto do desenvolvimento tecnológico da sociedade moderna - em se tratando da primeira metade do século XX, os impressos, o rádio, o cinema e outros dispositivos audiovisuais - poderiam contribuir para uma melhor formação, significando o fim de uma escola limitada ao professor e ao aluno, a lousa e ao giz. Em outros termos, deveriam ser capazes de colaborar na construção de uma nova sociedade, democrática, forjada para assumir um perfil urbano e industrial.

Nessa direção, em discurso proferido na inauguração da Biblioteca Escolar Fernando de Azevedo em São Paulo, em 15 de novembro de 1933, o autor ressalta a nova função do texto escolar na relação educativa, afirmando que a educação nova reabilita o livro com um novo papel, atribuindo-lhe o valor de "instrumento de trabalho". Para tal, diferencia o livro de texto, tido como o centro das atividades escolares, tal como se apresentava na escola tradicional; e o livro escolar que, segundo o autor, é um instrumento de trabalho que se desenvolve sob o impulso e em torno da criança, tal como propõe a Escola Nova.

Em tom de crítica, afirma que o livro de texto, na escola tradicional, bastava a si mesmo, com a sua "função absorvente, uniformizadora e autoritária". Ao impor ao aluno uma leitura desinteressante e sem sentido, feita por obrigação e não por prazer em descobrir algo novo, faz com que barreiras sejam criadas acerca da própria leitura, por parte dos alunos. 
Já o livro escolar, instrumento de trabalho da Escola Nova, deve ser elemento de cultura, que auxilia e completa as experiências vividas em sociedade, ou seja, "[...] completa e alarga a experiência que nos vem da observação direta e do trabalho, dos olhos, da mão e da ferramenta" (AZEVEDO, 1948, p. 202). É um instrumento que se utiliza como meio para se chegar a um fim, nunca como ponto de partida da aprendizagem. É um livro procurado pelo aluno, como forma de aprender e também de se divertir. Por isso

Bem vindos, sejam pois, à escola nova os livros de literatura, de ciências e de arte, em que a vida, surpreendida na complexidade de seus fenômenos e na variedade de seus aspectos, formiga de incidentes, de sugestões e de fatos, se alarga nos seus horizontes, se embebe nas sombras, se aprofunda nas observações da análise social [...].Os livros, assim entendidos, como obras de pensamento e de sensibilidade, de sentimento e de cultura, apropriados a cada idade, longe de acentuarem o divórcio entre a escola e a vida, só poderão contribuir para que uma e outra se aproximem e formem uma só e a mesma coisa, segundo os novos ideais pedagógicos, que são os vossos ideais e continuam a manter o mesmo prestígio e a mesma força de atuação (AZEVEDO, 1948, p. 202).

Em outro discurso publicado na obra A Educação e seus problemas, Fernando de Azevedo faz a crítica à escola tradicional e à escravização não só do aluno, mas também do professor perante o livro de texto. Segundo o autor, se o foco mudasse do professor tradicional, para a criança, respeitando sua "liberdade e espontaneidade", o livro de texto, antes usado como simples manual de conduta para o trabalho docente, deixaria de ser imposto ao aluno e seria usado como "instrumento de trabalho, veículo de informações e poderosa fonte de sugestões e estímulos" (AZEVEDO, 1948, p. 198).

Sobre esta perspectiva, cabem alguns comentários. Conforme exposto anteriormente, Alves (2015) considera que, de fato, na escola moderna, o trabalho didático não está centrado no professor ou no aluno, e sim no instrumento de trabalho, particularmente no manual didático, que determina ao professor inclusive a sua forma de utilização, com os chamados "guias do professor". Lembra ainda que

[...] na segunda metade do século XX, o Brasil intensificou o processo de expansão escolar, criando as condições materiais para, após mais de dois séculos, realizar a mesma plataforma de universalização da educação escolar proclamada por Comenius. Só no interior dessa plataforma os manuais didáticos, entre nós, foram conclamados a realizar as funções que lhes foram atribuídas pela escola moderna no século XVII. Eles simplificaram o trabalho do professor e assumiram centralidade na relação educativa (ALVES, 2015, p. 34).

Importa ainda esclarecer que Alves (2015), ao enfatizar a segunda metade do século XX como o momento histórico em que se deu o processo de expansão que criou as condições materiais para a intensificação do uso de manuais didáticos, refere-se particularmente ao ensino secundário. Considerando que as observações de Fernando de Azevedo referem-se ao ensino primário, este último iniciara seu processo de expansão já na Primeira República. 
Nesse sentido, o processo descrito por Alves e vivenciado por Azevedo, já entre os anos 1920 e 1930, mostra a expressiva utilização de manuais didáticos no ensino primário, ainda na primeira metade do século $\mathrm{XX}^{10}$, elemento já destacado neste artigo.

Cabe destacar a propriedade da crítica azevediana ao uso do manual didático já em sua forma mais desenvolvida, denominada por ele como livro de texto ou livro de leitura, inclusive mostrando o papel excludente deste instrumento de trabalho que, em outras palavras, afasta do trabalho didático exatamente aqueles elementos que, para Azevedo, poderiam ampliar o conhecimento, enriquecer a experiência do aluno, tornar a leitura atividade prazerosa e agradável - os livros de literatura, de ciência e de arte.

Tratando ainda do livro escolar, a ser utilizado no âmbito da Escola Nova, para Azevedo (1958), quando a leitura passa a ser prazerosa, torna-se interessante, pois se atribui sentido ao que está sendo exposto no livro. Isso só é possível quando é posto ao alcance da criança livros que lhes satisfaçam a curiosidade. Sendo assim, uma vez valorizado e devidamente utilizado o livro escolar, a biblioteca deixa de ser um "depósito" de livros velhos, que ninguém lê ou um lugar onde a criança é levada como forma de castigo por uma indisciplina em sala de aula, para dar lugar ao prazer, à descoberta de novos mundos e a novas possibilidades.

O mesmo acontece quando é proporcionado à criança o acesso ao cinema e ao rádio. Segundo o autor, estes instrumentos também fazem com que a criança expanda o seu horizonte de expectativa, pelo fato de adquirir uma nova sensibilidade diante das situações propostas a ela, instigando a sua curiosidade e, consequentemente, fazendo com que ela busque resposta às suas indagações.

Ora, considerando a importação desses recursos didáticos, para que a escola fosse capaz de produzir mudanças substanciais nas gerações futuras é preciso, segundo Azevedo, que haja uma reorganização no âmbito escolar, aparelhando-as com museus, laboratórios, bibliotecas, oficinas de trabalhos manuais e de campo, bem como as salas de jogos, para que estas sejam:

[...] excelentes e capazes de deixarem uma impressão indelével os primeiros contatos dos alunos com a escola e se abram, a cada criança, na vida escolar, todas as oportunidades de se desenvolver, segundo suas aptidões e uma direção que lhe seja própria. [...] a ação da escola se esterilizará, [...] se ela persistir em não se desenvolver "a par da marcha do mundo", em não se adiantar à evolução social ou, ao menos, em não acompanhá-la (AZEVEDO, 1948, p. 203).

Nesse momento, segundo o autor, havia dois lados de um mesmo país. Um já obsoleto, esvaindo-se em função de seu confronto com a industrialização e com a urbanização; e outro moderno, consequência desses dois processos, o que levaria, inevitavelmente, ao surgimento de novos fins sociais às instituições e aos indivíduos. Com as transformações pelas quais a sociedade vinha passando, provocadas pelo uso de meios de comunicação mais avançados naquele contexto (telégrafo, rádio, telefone), bem como a intensidade da vida moderna, abrir-se-iam novos desafios para a escola, que deveria acompanhar essas mudanças, rumo à conformação de um novo homem, expressão da urbanização e da industrialização.

Sobre esse conjunto de questões envolvendo o livro escolar e sua nova função na escola renovada, junto a outros recursos auxiliares, cabe ainda apresentar a análise exposta por Marx ao tratar do processo de produção capitalista. Assim, lembra que a forma como funcionam os componentes objetivos depende "[...] do papel que desempenham em cada 
caso num processo de trabalho determinado, [dependem] de sua função" (MARX, 2014, p. 315). Ora, uma vez mantida a mesma organização do trabalho didático, tal como se dava quando da apresentação da proposta azevediana, uma vez que se tratava ainda da sociedade capitalista; permanecendo as mesmas bases materiais que, no capitalismo, configuram uma dada relação educativa, que tem no texto escolar seu elemento central e determinante, mesmo a presença de novos recursos didáticos, ou de um livro de texto renovado, como desejava Azevedo, não seriam suficientes para impor a mudança desejada pelo escolanovista, em direção a uma escola do conhecimento. Assim, a função do manual didático na relação educativa, que o escolanovista acertadamente enxergava como excludente e autoritária, pois prendia aluno e professor, impedindo a ampliação de suas experiências, são mantidas porque não se transformou a organização do trabalho didático que lhe dá vida e sentido, no interior da sociedade capitalista.

E tais limites também se manifestarão quando o autor remete essa mudança, de caráter mais amplo, à reflexão sobre o papel do Estado e das políticas educacionais, o que terá consequências nas suas análises sobre o terceiro aspecto do trabalho didático a ser apresentado neste artigo: a questão do espaço físico.

\section{Espaço Físico}

O terceiro aspecto da organização do trabalho didático a ser tratado é o espaço físico. E, conforme já foi dito, cada momento histórico produz o espaço que lhe é peculiar. Assim pergunta-se: que espaço físico era peculiar à Escola Nova? Como Fernando de Azevedo pensou este espaço?

Em discurso proferido em setembro de 1927, durante sua permanência como DiretorGeral da Instrução Pública do Distrito Federal, ele expunha a situação dos prédios escolares naquele município:

\footnotetext{
Se o que me feriu o espírito, no primeiro relance das inspeções "de contato", foi o aspecto material, mais acessível à observação, não é, porém, o mais grave nem o mais desconcertante. Certo as escolas instaladas, em sua maioria, em velhas edificações de aluguel carcomidas, e às vezes mesmo em ruína, ou em prédios mal adaptados aos fins escolares, constituem, com seu ar de abandono e com o seu caráter provisório, que se refletem nos edifícios e em todas as suas instalações, um atentado clamoroso aos nossos foros de cultura e a todos os princípios rudimentares de higiene, conforto e educação (AZEVEDO, 1958, p. 43).
}

Para ele, uma instituição escolar não pode funcionar com eficácia, dentro de seus objetivos, sem prédios e instalações adequadas. Assim, organizar e instalar, nas palavras de Azevedo, são dois aspectos de um problema único: "se instalarmos bem as escolas, sem lhe termos dado organização eficiente, e dentro de ideais modernos, teremos escolas fachada".

Conforme os levantamentos realizados em 1927, o número de escolas ultrapassava 230, mas apenas 90 funcionavam em prédios próprios. Destes, não mais que 20 foram Revista HISTEDBR On-line, Campinas, $n^{\circ}$ 71, p. 93-116, mar. 2017 - ISSN: 1676-2584 
especialmente edificados para escola, a maioria mal projetados, construídos no alinhamento das ruas, em faixas de terrenos sem recreios e campos de jogos e sem reservas de espaços livres. Os melhores prédios escolares, afirma Azevedo (1958), embora de fachada imponente e grande volume de massas têm:

[...] pequenas áreas internas e reduzido espaço para recreios, com suas salas de aula mal arejadas e iluminadas, apertadas entre corredores e vestíbulos, não permitem a população escolar, fechada entre paredes, o contato com a natureza e a liberdade e alegria dos exercícios ao ar livre (AZEVEDO, 1958, p. 133).

Assim, a constatação do estado caótico dos prédios escolares existentes no Rio de Janeiro levou a Diretoria-Geral de Instrução Pública a organizar uma política de construção escolar para a cidade. Era necessário construir e instalar cerca de 100 novos prédios escolares, contudo, a situação financeira da municipalidade não estava preparada para tanto. Portanto, buscou-se 'fazer um esforço supremo para 'começar' a resolver o problema, atacando as primeiras grandes construções por normas e princípios que pudessem construir uma nova política de edificações escolares" (AZEVEDO, 1958, p. 134).

Pelas exigências da Escola Nova, às instituições escolares não faltariam: salas de clínica e assistência dentária, o pavilhão de ginástica ou ginásio, o museu, a biblioteca e as oficinas de trabalhos manuais e de pequenas indústrias. Desta forma, a reforma do ensino consagrou, em seu artigo $601^{\circ}$, o princípio fundamental de que cada escola deve ter seu prédio próprio, proibindo a compra de prédios de moradia ou adaptações de prédios municipais. Segundo os preceitos escolanovistas, as escolas, tanto o prédio quanto suas instalações, "[...] devem constituir, para os alunos, ambientes de conforto e de repouso, próprios à conservação e o desenvolvimento da saúde" (AZEVEDO, 1958, p. 135). É necessário ainda que o ambiente em que se desenvolve a atividade do aluno seja calmo, agradável e pitoresco. Buscava-se o ambiente ideal às novas funções que a escola deveria assumir.

Além disso, continua, a edificação escolar deve contribuir para a educação estética por sua arquitetura e sua decoração, pois “'[...] não há meio mais eficaz para educação do gosto popular do que por, sob seus olhos, nos edifícios públicos e, sobretudo, naqueles destinado à educação popular" (AZEVEDO, 1958, p. 137). A escola primária, na sua feição tradicional, não atendia a esses preceitos estéticos. Essa nova política, assim, obedecia ao princípio fundamental de que o prédio escolar, além de atender às exigências elementares de ordem técnica e pedagógica, deve acatar também as exigências estéticas, pela arquitetura e decoração.

Confirmando as dificuldades para a materialização de seus princípios, na administração de Azevedo "concluíram-se nove obras, contabilizadas entre anexos a prédios construídos como escolares em gestões anteriores e edifícios novos" (IEB, 2016, p. 12).

A Escola Normal foi o primeiro alvo. A inspiração para a construção da Escola Normal, assim como dos demais edifícios escolares, será o estilo tradicional brasileiro, mas prevalecendo o critério do ambiente educativo. Nessa concepção, o edifício deverá inspirar uma forte e luminosa lição de higiene e civismo, mostrando à sociedade o gosto nacional $\mathrm{e}$ incentivando, consequentemente, o cultivo e a admiração das tradições brasileiras.

$\mathrm{Na}$ sequência do texto, Azevedo descreve o projeto arquitetônico da Escola Normal, em que condensaram seus princípios para a arquitetura escolar: beleza arquitetônica, que seja ela mesma expressão do belo e da nacionalidade, em um espaço cuja finalidade educativa seria o vetor fundamental para as escolhas de caráter técnico - disposição das 
salas, aparelhamento dos espaços, espaços de convivência, entre outros - não podendo deixar de estar presente a biblioteca, o espaço audiovisual, etc.:

O edifício terá um pátio central, no andar térreo, ponto de confluência da população escolar, circundado de colunas em arcaria. No primeiro andar, na parte correspondente a este pátio, uma loja com colunas, guarnecida de balcões. No terceiro andar, em sítio correspondente, a mesma disposição. Aí, as paredes internas serão cobertas de azulejos, em que se reproduzirá, em sequência expressiva, rigorosamente lógica, através de quadros episódicos, a evolução social e política da nacionalidade; uma lição simbólica que seja, ao mesmo tempo, de pura arte. [...] Na mesma ordem de ideias, sobre organização técnica, procuraremos afastar do movimento de ensino toda monotonia. Cada disciplina terá a sua sala de aula, e cada sala um ambiente educativo próprio, o que evitará a fadiga sensitiva do aluno e suscitará a facilidade de assimilação da matéria versada. Toda a sala de aula terá, ainda, uma biblioteca especializada, o que facilitará extraordinariamente ao professor o acessório documentário da preleção (AZEVEDO, 1958, p. 215).

A grandiosidade do edifício escolar pensada por Azevedo nos remete aos "palácios do saber", construídos nos primeiros anos da República. Mas não foram os grupos escolares, com sua arquitetura e seus recursos didáticos, considerados como escola tradicional pelos escolanovistas? Parafraseando o escritor português Alexandre Herculano (1965), parece que sob os fundamentos escolanovistas jazem as cinzas dos paradigmas que o precederam.

Em 1933, Fernando de Azevedo assumiu a Direção-Geral da Instrução Pública do Estado de São Paulo. Seu interesse era de uma "[...] transformação radical, de estrutura, mentalidade e técnicas de ensino e educação em escolas de todos os tipos e níveis. Daí a ideia de um Código de Educação" (AZEVEDO, 1971, p. 116). Conforme dito anteriormente, em abril de 1933, o Decreto no 5.884 instituiu o Código de Educação do Estado de São Paulo.

O espaço físico é contemplado na Primeira Parte, no Capítulo I, Título 5 - Do Serviço de Prédios e Instalações Escolares. Conforme o Código, as instalações escolares têm que "[...] possuir instalações próprias e dar a cada prédio as condições higiênico-pedagógicas que façam dele centro de saúde e alegria, ambiente de educação estética e fator de nacionalização" (artigo 32). Os artigos 33 e 34 determinam as atribuições do chefe de serviço o qual "orientará e coordenará todos os trabalhos mediante processos racionais de inquérito, investigação e estatística, [...] atraindo todas as forças sociais capazes de contribuir para a solução do problema dos prédios escolares" (artigo 34). O Diretor-Geral do Departamento de Educação designará uma comissão permanente que cuidará das condições higiênicopedagógicas dos prédios a serem construídos, organizará e fiscalizará a execução de um plano para a solução progressiva do problema das construções escolares (Artigo 35).

Voltando às questões que deram início a este item - que espaço seria peculiar à Escola Nova - a princípio tem-se que a peculiaridade do espaço escolar, dentro dos princípios escolanovistas, deveria atender tanto as exigências de ordem técnica e pedagógica, quanto primar pela estética. A escola deveria ser um ambiente confortável, repousante, saudável atender as condições higiênicas - ser calmo, agradável, pitoresco, além de ser um fator de nacionalização. No entanto, pelo exposto anteriormente, limites financeiros pesaram, pelo menos no Distrito Federal, para a efetivação dessa proposta.

Azevedo destaca as instalações escolares, dessa forma, como um dos mais graves problemas da educação, contudo, reconhece que sua solução não implicaria a resolução do 
problema da educação com um todo. Haveria que se resolver também, as questões técnicas, pois falta "[...] na sua organização e no seu funcionamento normal, [o] caráter científico e moderno" (AZEVEDO, 1958, p. 132). Mais que isso, como já afirmado, demandaria políticas educacionais permanentes, voltadas para as edificações escolares.

Tendo sido apontadas pelo autor, em vários momentos de sua argumentação, como elemento fundamental para a nova organização do trabalho didático que se almejava, qual o papel das políticas educacionais para Azevedo?

\section{O lugar das políticas educacionais}

Como lembra Alves (2012), as políticas educacionais, na medida em que são parte integrante da esfera de programação do trabalho didático, tornam-se elementos importantes para a análise deste último. Ainda mais quando, seguindo uma tendência mais geral do capitalismo, a saber, o aprofundamento da divisão do trabalho - "distanciaram-se, portanto, as esferas de programação e de execução do trabalho didático, a tal ponto que se tornaram também distintos e especializados os seus respectivos espaços" (ALVES, 2012, p. 176).

Diante disso, não é estranho que Fernando de Azevedo tenha dado especial atenção ao papel desempenhado pelos órgãos diretivos e às diretrizes políticas por eles estabelecidas. Ainda mais, isso também pode explicar a sua aproximação, em toda a sua vida, da atividade política, em diferentes níveis (AZEVEDO, 1971).

Ora, ao se tratar de políticas educacionais, é impossível não remeter a discussão ao papel do Estado frente à questão educacional, elemento primordial desse debate. Nesse sentido, baseando-se numa perspectiva ontológica que destaca o ser moral da sociedade como o elemento que deverá ser transformado em sua essência pela educação, Azevedo coloca o Estado no centro desse processo, como elemento impulsionador e diretor dessa mudança:

A escola é, pois, envolvida e dirigida por uma realidade moral que a ultrapassa: é a realidade nacional. A escola organiza-se, constrói-se, mas dentro dos limites que lhe fixa, segundo as fôrças com que a impele, e no sentido a que a orienta, essa realidade coletiva, que é seu próprio habitat, e como que a terra, em que ela embebe suas raízes e a atmosfera, o "ar público" em que respira (AZEVEDO, 1948, p. 97).

Funcionar como guardião, aquele a quem cabe resguardar o "ar público", é exatamente esta a função do Estado, para o referido educador. O que seria a questão pública? Para Azevedo, aquelas esferas da vida social que afetam a vida de muitos, de tal forma que se torna necessário cuidar das mesmas. Assim, a expansão quantitativa da escola, quando essa tarefa formativa saiu da esfera privada, familiar, passando a ser oferecida a muitos, levou a educação, em particular a educação escolar, para a esfera pública, já no momento histórico em que se consolidou a sociedade capitalista.

Importa frisar ainda que essa proposta tem duas implicações fundamentais: 1) que a escola e o Estado que a dirige não podem se voltar para os interesses particulares de uma classe. Isso significa reconhecer o conflito entre o interesse público, interesse geral, fundado no Estado, e o interesse particular, cujo locus é a própria sociedade, fundada com base em interesses privados; 2) e que o reconhecimento desse conflito, inerente à sociedade de classes, sobreleva a função do Estado, este último responsável por harmonizar/coordenar os 
interesses de classes diferentes, assumindo sua função pública, ou seja, fazendo valer o interesse geral. Em outras palavras, o Estado atuaria como mediador/regulador de conflitos entre os interesses privados, promovendo o equilíbrio entre autoridade/liberdade.

Assim, o Estado deve transformar a luta dos entes privados em um elemento harmônico, construtivo para a vida social. No caso da educação, a escola seria a síntese construtiva dos diversos, atendendo a variedade de interesses de os distintos grupos sociais, nos seus pontos de intersecção com os interesses gerais, segundo Azevedo (1948). Para tal, caberia ao Estado oferecer educação a todos, uma vez que a escola seria elemento próprio da esfera pública da vida social.

Para cumprir essa tarefa, no entanto, Azevedo (1948) enfatiza a importância de certos elementos, destacando-se a questão do financiamento. Nesse sentido, o papel do Estado como provedor da educação comum depende da sua capacidade de manter as condições materiais e técnicas adequadas para tal. Isso inclui todo o material de apoio existente nas escolas - além do livro escolar, as bibliotecas, o cinema, o rádio, entre outros; e das condições técnicas para utilizá-los, o que exigiria pessoal de apoio e adequada preparação do corpo docente.

Outro elemento importante para o qual concorreria a política educacional, na perspectiva de formação da nacionalidade, seria sua atuação em duas vertentes: formação e seleção das elites, por um lado e educação popular em larga escala, por outro. Para isso, seria essencial a organização estrutural de um sistema nacional de ensino, cujo elemento estruturante seria o plano de educação, orgânico e flexível, capaz de abranger a variedade de sistemas existentes no país. Ou seja, o desafio era a organização de um sistema nacional, não a escola de uns, mas a escola para todos - papel que caberia ao Estado. Chama ainda à discussão, nesse aspecto, para a importância da "dialética" centralização/descentralização ou seja, relações federativas que permitam manter a unidade moral e, ao mesmo tempo, atender as peculiaridades do país (os contextos urbanos e rurais, as distintas regiões etc.).

Se a determinação política se espraia sobre todo o tecido social e educacional, sua influência também se faz sobre as sobre as técnicas educacionais - processos de ensino, programas escolares, técnicas de organização e trabalho são determinadas pelas políticas de educação. Daí que somente uma política educacional fortemente amparada em firme terreno filosófico, impregnado pela convicção do papel do ensino comum na criação da consciência nacional, e da importância do Estado para que tal ocorra, pode conduzir o veio das "individualidades nacionais" ao encontro da solidez moral do "bem público" (AZEVEDO, 1948).

E como essa tarefa de convencimento do cidadão acerca da importância da educação implica transformar consciências e comportamentos, uma política de educação é simultaneamente uma política de cultura - além da escola, atingirá o cinema, a rádio, o livro, o teatro, a imprensa, numa empresa comum voltada ao fortalecimento do interesse comum.

Finalmente, importa lembrar mais uma vez que todos os elementos pertinentes à organização do trabalho didático - espaço físico, infraestrutura (livros escolares, material de apoio, bibliotecas, entre outros), contratação e formação de professores, etc., para Fernando de Azevedo, têm nas políticas educacionais seu espaço de inflexão. Por isso chama a atenção para o fato de que as disputas, no campo educacional, dar-se-iam em torno do Estado e do acesso aos bens públicos. Assim, seriam as políticas educacionais e não a estrutura pedagógica, o elemento crucial para se evidenciar o que são as escolas de um país - seriam estas que determinariam os erros de sua estrutura e a anomalia de seu funcionamento.

Por isso a alusão, numa perspectiva que se aproxima de toda a tradição liberal, por um lado, a um Estado que se comporta, simultaneamente, como tertius entre os interesses privados e os interesses comuns e como árbitro e defensor do bem comum. Por outro, num 
momento histórico que colocava o país nos caminhos do social-desenvolvimentismo, Azevedo apoia a proposição de um Estado que também intervêm, seja para sustentar o desenvolvimento nacional, visto como elemento necessário para a construção da nova sociedade; seja para organizar, moral e financeiramente, este processo de reconstrução nacional.

\title{
Considerações finais
}

Iniciam-se as considerações finais deste trabalho expondo-se a reflexão de Alves (2001), ao tratar da expansão da escola mantida pelo Estado que, no Brasil como em outras partes do mundo capitalista, caracterizou-se também pela generalização do uso dos manuais didáticos. Tal processo de expansão, em diferentes momentos históricos - a partir do final do século XIX nos países centrais do capitalismo, nos albores do século XX, no Brasil deu-se sobre a égide da universalização dos instrumentos de trabalho que marcam a escola moderna, fundamentalmente, o manual didático. E, nesse sentido,

\begin{abstract}
Os manuais que se universalizaram com o escolanovismo, acentue-se, em nada se diferenciavam, quanto à concepção, daqueles criados e alardeados por Comenius. A diferença referia-se somente à amplitude de sua utilização. No último terço do século XIX [nos países capitalistas centrais] difundiram-se em escala mundial, ao passo que, até então, estavam presentes no trabalho didático de restritos focos regionais [...]. Importa reconhecer, ainda, que o mestre, fruto de uma nova relação com os instrumentos de trabalho, estava começando a submeter-se a um processo que, tendencial e gradativamente, iria restringir o seu domínio teórico, as suas habilidades técnicas e, portanto, a sua autonomia em face do trabalho didático (ALVES, 2001, p. 173).
\end{abstract}

Ou seja, o processo de aprofundamento do capitalismo, em sua fase monopólica, solapa quaisquer ilusões acerca das possibilidades de produzirem-se "manuais científicos" (BRITO, 2010), como era o desejo de Fernando de Azevedo, que efetivamente fez a crítica do manual didático na organização do trabalho didático manufatureiro, denunciando seus efeitos deletérios em relação às possibilidades de educar-se para a sociedade "democrática". Expõe, inclusive, a dificuldade de produzir compêndios, já em 1951, quando no prefácio à segunda edição do texto escolar Sociologia Educacional (1951, p. 8), esclarece que "Certos editôres o quereriam mais magro e enxuto...”. Resiste, no entanto, negando-se a produzir "manuais de tipo elementar", os livros de texto que já combatia desde os anos 1930.

De fato, os novos tempos que a Escola Nova anunciava esbarravam nas bases materiais capazes de dar suporte para a tarefa de construir uma escola única e cidadã. Essa questão envolve dois aspectos. Por um lado, a materialidade do trabalho didático erigida pela sociedade capitalista, "[...] que envolve desde a relação educativa, os procedimentos do professor, os conteúdos didáticos, as tecnologias educacionais, o espaço físico da sala de aula e o aparato administrativo que zela pela manutenção da ordem que lhe é imanente" 
(ALVES, 2015, p. 35) constituem e implicam-se dialeticamente, no sentido de reforçar o existente. Não bastaria, conforme a proposta azevediana, mudar um desses elementos, por mais expressivo que seja - como é o caso das edificações escolares ou da formação de professores - pois o seu conjunto reage na perspectiva da conservação.

Por outro lado, Fernando de Azevedo chama a atenção, no caso das políticas educacionais, para um elemento que seria cada vez mais decisivo no capitalismo que transitava para a segunda metade do século XX: a disputa em torno dos fundos públicos, no contexto educacional, sobretudo quando se acentuou o processo da expansão da escolarização primária. Isso criou as condições necessárias para a formação de novos setores relacionados à produção e comercialização de recursos didáticos, tais como a indústria gráfica e os manuais didáticos; a indústria da construção civil e as edificações escolares, entre outros. Consequentemente, partes significativas dos recursos estatais que Azevedo e outros escolanovistas projetavam que fossem chegar à escola pública foram solapadas pelo capital, terminando por determinar em que medida os financiamentos públicos estarão disponíveis para outras necessidades, como a formação de professores, por exemplo.

Azevedo, contudo, continua preso à crença de que a formação de elites cidadãs, por meio da educação, seria o elemento fundamental para alavancar a reforma moral pela qual lutou ao longo de sua vida, reforma moral esta que colocaria as políticas educacionais do país no compasso das transformações requeridas pela sociedade urbana e industrial para a qual o Brasil caminhava. Uma vez mudado o edifício político, todo o restante acompanharia tais transformações.

O que Azevedo não podia enxergar é que, para tal mudança, seria necessário um projeto político mais amplo, de fato interligado a um processo de transformações que não tivesse em foco apenas a educação, mas, o conjunto da construção capitalista desde suas fundações, colocando, dessa forma, outro conjunto de homens na direção e organização da sociedade, desde a sua base material até seus elementos superestruturais - a educação aí incluída. Como lembra Gramsci (2006, p. 45), ao comentar a reforma Gentile, ocorrida na Itália entre 1922 e 1923,

A luta contra a velha escola era justa, mas a reforma não era uma coisa tão simples como parecia; não se tratava de esquemas programáticos, mas de homens, e não imediatamente dos homens que são professores, mas de todo o complexo social do qual os homens são expressão.

No entanto, os limites do pensamento liberal de Fernando de Azevedo não poderiam abarcar tal reflexão.

\section{Referências}

ALVES, G. L. A produção da escola pública contemporânea. Campo Grande: UFMS; Campinas: Autores Associados, 2001.

ALVES, G. L. O Trabalho Didático na Escola Moderna: formas históricas. Campinas: Autores Associados, 2005.

ALVES, G. L. Organização do trabalho didático: a questão conceitual. Acta Scientiarum. Education, Maringá, v. 34, n. 2, p. 169-178, jul./dez. 2012. Disponível em: <http://periodicos.uem.br/ojs/index.php/ActaSciEduc/article/view/17180/9978>. Acesso em 15 out. 2014. 
ALVES, G. L. Textos escolares do ensino secundário no Brasil: da época jesuítica aos nossos dias. In: (Org.). Textos escolares no Brasil: clássicos, compêndios e manuais didáticos. Campinas: Autores Associados, 2015. p. 5-60.

ARAÚJO, M. M. de. Breves notas sobre a criação da Federação Nacional das Sociedades de Educação (FNSE) por Vicente Licínio Cardoso e José Augusto Bezerra de Medeiros. Apresentado no $2^{\circ}$ Congresso Luso-Brasileiro de História da Educação. São Paulo. Faculdade de Educação, USP. 16 a 19 de fevereiro de 1998.

AZEVEDO, F. de. A Educação e seus Problemas. 4.ed. São Paulo: Melhoramentos, 1948. tomo 1. (Obras Completas de Fernando de Azevedo, v. 8).

AZEVEDO, F. de. A Educação na Encruzilhada. 2.ed. São Paulo: Melhoramentos, 1960.

AZEVEDO, F. de. Novos Caminhos e Novos Fins. 3.ed. São Paulo: Melhoramentos, 1958. (Obras Completas de Fernando de Azevedo, v. 7).

AZEVEDO, F. de. História da Minha Vida. Rio de Janeiro: José Olympio, 1971.

AZEVEDO, F. de. Princípios de Sociologia: pequena introdução ao estudo de Sociologia Geral. São Paulo: Companhia Editora Nacional, 1935.

AZEVEDO, F. de. Sociologia Educacional: introdução ao estudo dos fenomenos educacionais e de suas relações com os outros fenomenos sociais. São Paulo: Companhia Editora Nacional, 1940.

BRITO, S. H. A. de. A produção de manuais didáticos e o ensino de Sociologia na escola média em dois momentos históricos (1935-1989). Revista Histedbr On Line, Campinas, número especial, p. 58-75, maio 2010.

BRITO, S. H. A. de., et al. O manual didático como instrumento de trabalho nas escolas secundária e normal (1835-1945). Campo Grande: 2012. Relatório de pesquisa.

CAMARA, S. A Reforma Fernando de Azevedo e as Colmeias Laboriosas no Distrito Federal de 1927 a 1930. In: MIGUEL, Maria Elisabeth Blanck et al. Reformas educacionais: as manifestações da Escola Nova no Brasil (1920 a 1946). Uberlândia: Edufu; Campinas: Autores Associados, 2011. p. 177-196.

COMÉNIO, J. A. Didáctica Magna. 5.ed. Lisboa: Calouste Gubelkian, 2006.

CONGRESSO LUSO-BRASILEIRO DE HISTÓRIA DA EDUCAÇÃO, 2, 1998. Atas... São Paulo: FEUSP, 1998. p. 414-419

CORDEIRO, C. N. H. Arquitetura escolar de Mato Grosso e Mato Grosso do Sul 19101990: primeiras anotações. Intermeio, Campo Grande, v. 1, n. 1, p. 17-24, 1995.

EVANGELISTA, O.; LIMA, S. Fernando de Azevedo: sociólogo e educador. Florianópolis: EdUFSC, 2008. 
FERNANDES, E. Métodos e conteúdos de alfabetização em manuais didáticos nos séculos XIX e XX: de Calkins a Lourenço Filho. Campo Grande: 2014. Tese (Doutorado em Educação) - Universidade Federal de Mato Grosso do Sul.

GRAMSCI, A. Cadernos do cárcere. 4.ed. Rio de Janeiro: Civilização Brasileira, 2006. v. 2: Os intelectuais. O princípio educativo. O jornalismo.

HERCULANO, Alexandre. O Monge de Cister. Rio de Janeiro: Tecnoprint, 1965.

HOUAISS, A.; VILLAR, M. de C. (Orgs.). Grande Dicionário Houaiss da Língua Portuguesa. Rio de Janeiro: 2001. Disponível em:

<https://houaiss.uol.com.br/pub/apps/www/v3-0/html/index.htm\#2>. Acesso em 2 abr. 2016.

IEB [Instituto de Estudos Brasileiros]. Arquivo Fernando de Azevedo. Disponível em: <http://www.usp.br/niephe/publicacoes/docs/REFORMA.PDF>. Acesso em: 15 mar. 2016.

KOSIK, K. Dialética do concreto. 2. ed. Rio de Janeiro: Paz e Terra, 1976.

MARX, K. El capital: libro 1, capitulo VI inedito. 3. ed. Buenos Aires: Siglo Veintiuno, 1974.

MARX, K. O capital: crítica da Economia Política. São Paulo: Boitempo, 2014. Livro 2: o processo de circulação do capital.

MARX, K.; ENGELS, F. A ideologia alemã: crítica da mais recente filosofia alemã em seus representantes Feuerbach, B. Bauer e Stirner, e do socialismo alemão em seus diferentes profetas (1845-1846). São Paulo: Boitempo, 2007.

NAGLE, J. Educação e sociedade na Primeira República. 2.ed. Rio de Janeiro: DP\&A, 2001.

NERY, A. C. B. A Sociedade de Educação de São Paulo: embates no campo educacional (1922-1931). São Paulo: Unesp, 2009.

PENNA, M. L. Fernando de Azevedo: educação e transformação. São Paulo: Perspectiva, 1987.

SÃO PAULO [Estado]. Diretoria-Geral da Instrução Pública. Código da Educação do Estado de São Paulo. São Paulo: 1933. Disponível em: <http://www.al.sp.gov.br/repositorio/legislacao/decreto/1933/decreto-588421.04.1933.html>. Acesso em: 8 abr. 2016.

SANTOS, M. L. C. K. Lendo com Hilda: João Köpke - 1902. Campinas: 2013. Tese (Doutorado em Educação) - Universidade Estadual de Campinas. Disponível em: <http://repositorio.unicamp.br/jspui/handle/REPOSIP/250825>. Acesso em 20 nov. 2016. 
SILVA, A. L. da M. A Sociologia Educacional de Fernando de Azevedo: Formação de Professores e Intelectuais. Campo Grande: 2016. Tese (Doutorado em Educação) Universidade Federal de Mato Grosso do Sul.

TOTTI, M. A. Raízes do Pensamento Educacional de Fernando de Azevedo. Araraquara: 2003. Dissertação (Mestrado em Educação Escolar) - Programa de Pós-Graduação em Educação Escolar, UNESP. 


\section{Notas}

${ }^{1}$ Doutora em Filosofia e História da Educação, professora do Curso de Ciências Sociais e Programa de PósGraduação em Educação do Centro de Ciências Humanas e Sociais da Universidade Federal de Mato Grosso do Sul, campus de Campo Grande/MS, é ainda membro do GT MS do HISTEDBR. Universidade Federal do Mato Grosso do Sul (UFMS) E-mail: silvia.brito@ufms.br.

${ }^{2}$ Doutora em Filosofia e História da Educação, professora do Curso de Pedagogia do Centro de Ciências Humanas e Sociais da Universidade Federal de Mato Grosso do Sul, campus de Campo Grande/MS, é ainda membro do GT MS do HISTEDBR. Universidade Federal do Mato Grosso do Sul (UFMS) E-mail: maria.cardoso@ufms.br.

${ }^{3}$ Licenciada em Letras, discente do Curso de Pedagogia da Universidade Federal de Mato Grosso do Sul, campus de Campo Grande/MS, foi bolsista de Iniciação Científica pelo Programa PIBIC/CNPq/UFMS entre 2015 e 2016. Universidade Federal do Mato Grosso do Sul (UFMS) E-mail: rose_oliveira_2010@hotmail.com.

4 “A Federação Nacional das Sociedades de Educação (FNSE) foi fundada em 31 de julho de 1929, por Vicente Licínio Cardoso, após desentendimentos com a ABE [Associação Brasileira de Educação) sobre fundar uma federação que congregasse os departamentos estaduais da ABE" (NERY, p. 46). Existiu até 1933, quando o grupo liderado por Anísio Teixeira e Carneiro Leão, dirigindo a ABE, recolocou esta última na condição de liderança do movimento educacional no país, reagrupando os educadores da FNSE (ARAÚJO, 1998).

${ }^{5}$ Este trabalho é fruto das pesquisas realizadas no âmbito do projeto intitulado "A organização do trabalho didático na perspectiva de educadores da Escola Nova (1930-1970)", financiado por meio da Chamada MCTI/CNPQ/MEC/CAPES nº 22/2014 - Ciências Humanas, Sociais e Sociais Aplicadas - coordenado pela Profa. Dra. Carla Villamaina Centeno/UEMS e desenvolvido por pesquisadores do Grupo de Estudos e Pesquisas "História, Sociedade e Educação no Brasil" - HISTEDBR/GT MS.

${ }^{6}$ Para o presente trabalho foi utilizada a terceira edição, de 1958.

${ }^{7}$ Assinale-se que foi utilizado para este artigo o tomo 1 da quarta edição, de 1958, que foi revista e atualizada pelo autor, acrescentando alguns textos em relação à edição original.

${ }^{8}$ Sem que faça alusão direta a isso, pela amplitude que Azevedo atribui às tarefas e espaço social da escola na vida dos alunos, pode-se pressupor que isso só se efetivaria, mesmo que de forma progressiva, numa escola de tempo integral.

${ }^{9}$ Além do já citado Princípios de Sociologia (1935), também produziu o compêndio Sociologia Educacional (1940).

${ }^{10}$ Nessa direção, Fernandes vai analisar os manuais didáticos utilizados na transição do século XIX para o XX, no processo de alfabetização, em particular aquele representado pelo texto Primeiras Lições de Coisas, de Norman Alisson Calkins; e Cartilha do Povo e Testes ABC, ambos de Manuel Bergström Lourenço Filho, publicados pela primeira vez em 1929 e 1933, respectivamente (FERNANDES, 2014).

Recebido: Abril/2017.

Aprovado: Junho/2017. 